For: Journal of Insect Physiology as Original Research Article

Send correspondence to:

Patricia Tamez Guerra

AP 46-F. FCB-UANL

San Nicolás de los Garza, N. L.

México. 64451.

Phone (0115281) 8376-4319

Fax (0115281) 8352-4212

patricia.tamezgr@uanl.edu.mx

patamez@hotmail.com

\title{
Regulation by gut bacteria of immune response, Bacillus thuringiensis susceptibility and hemolin expression in Plodia interpunctella
}

Alonso A. Orozco-Flores ${ }^{1}$, Jose A. Valadez-Lira ${ }^{1}$, Brenda Oppert ${ }^{2}$, Ricardo Gomez-Flores ${ }^{1}$, Reyes Tamez-Guerra ${ }^{1}$, Cristina Rodríguez-Padilla ${ }^{1}$, and Patricia Tamez-Guerra ${ }^{1 *}$

${ }^{1}$ Universidad Autónoma de Nuevo León, Departamento de Microbiología e Inmunología, Facultad de Ciencias Biológicas, Cd. Universitaria, San Nicolás de los Garza, N. L. México. 66455.

${ }^{2}$ USDA, Agricultural Research Service, Center for Grain and Animal Health Research, 1515 Collage Ave., Manhattan, Kansas, 66502 USA.

*Corresponding author. 


\begin{abstract}
Plodia interpunctella (Hübner) is an important stored grain insect pest worldwide, and the first lepidopteran with reported resistance to Bacillus thuringiensis $(B t)$ toxins. Since gut bacteria may affect $B t$ insecticidal activity, we determined whether $P$. interpunctella lacking gut bacteria had differences in immune responses and susceptibility to a $B t$ formulation, Bactospeine. To clear the gut bacteria, third instar larvae were reared on artificial diet using antibiotics, or were from sterilized eggs and reared under sterile conditions, and larvae were fed diets with or without Bt. Mortality was significantly lower $(p<0.05)$ in bacteria-free larvae (either fed antibiotics in diet or from sterilized eggs and diet) treated with $\mathrm{Bt}$, compared to larvae with gut bacteria and treated with Bt. The number of hemocytes was lower in control and Bt-treated larvae, but was significantly higher $(p<0.001)$ in larvae treated with antibiotics and $B t$, and larvae from presterilized eggs and reared on sterile diet had the highest number of hemocytes. Phenoloxidase activity was significantly lower $(p<0.05)$ in Bt-treated larvae from presterilized eggs reared on antibiotics for $24 \mathrm{~h}$ or in larvae reared on antibiotic-treated diets prior to $B t$ introduction compared to those fed control diet. Hemolin gene expression was reduced in larvae fed $B t$ diets compared to control and was not detected in larvae treated with antibiotics. Larvae from sterilized eggs and fed sterile diet never reached the pupal stage. Therefore, the loss of gut bacteria in $P$. interpunctella larvae affected the host immune response and expression of the hemolin gene, and greatly reduced susceptibility to $B t$.
\end{abstract}

Keywords: Bt-resistance; gut bacteria; hemocytes; phenoloxidase activity. 


\section{Introduction}

The Indianmeal moth, Plodia interpunctella (Hübner) (Pyralidae), is an insect pest of stored grains and flour, and also attacks garlic bulbs and packaged goods. Every year, millions of dollars are lost worldwide due to P. interpunctella (Mohandass et al., 2007). Organic insecticides used to control this pest include the entomopathogenic bacteria Bacillus thuringiensis $(\mathrm{Bt})$ Berliner.

Some studies have suggested that gut bacteria are important in the insect response to Bt. When gut bacteria were eliminated by antibiotic-supplied diets, susceptibility to $B t$ was significantly reduced in Lepidoptera species (Broderick et al., 2006, 2010). Their findings were in contrast to those of Frankenhuyzen et al. (2010) and Johnston and Crickmore (2009), who related changes in the susceptibility of insects to $B t$ that were independent from microbiota, but instead were associated with the effect of antibiotics in the insect. Recently, expression of an immunity gene was decreased by RNAi in Spodoptera littoralis Boisduval, with a concomitant increase in susceptibility to $B t$ that was linked to the proliferation of bacteria in the gut, contributing to septicemia (Caccia et al., 2016). Bt toxicity may depend on direct or indirect interaction between the entomopathogen and the intestinal microbial community, as bacteria are associated with growth and development, and may contribute to reproduction, digestion, nutrition, and pheromone production (Dillon and Dillon, 2004).

The pattern recognition receptors of the insects' immune system recognize bacterial peptidoglycans, resulting in signal transduction, which in turn results in induction of the immune response, such as the production of antimicrobial peptides (AMPs) (Kim et al., 2008). The humoral component of the immune response includes increased production of AMPs and induction of phenoloxidase (PO) cascade-mediated melanization, whereas the cellular response 
involves phagocytosis by circulating hemocytes (Kim et al., 2008; Vizioli and Salzet, 2002), cell aggregation, nodulation, and encapsulation (Lavine and Strand, 2002). In addition, endosymbiotic bacteria were reported to regulate insect immune defense mechanisms, like melanization, against pathogens and parasites (Eleftherianos et al., 2013).

Knowledge of pest intestinal bacteria and how they affect $B t$ susceptibility, perhaps through an indirect immune response, could lead to new strategies for control. High expression of five different AMPs was reported in Trichoplusia ni Hübner strains with low susceptibility to Bt (Tamez-Guerra et al., 2008). However, these insects also had a decreased immune response (reduction in hemolymph protein concentrations, PO activity and the number of circulating hemocytes) after exposure to low $B t$ doses, and this may reflect a fitness cost associated with $B t$ resistance (Ericsson et al., 2009). In P. interpunctella, the expression of hemolin has been reported during development and was related to bacterial challenge (Aye et al., 2004). We found that hemolin transcript amplification was significantly different between Bt-susceptible and Btresistant $P$. interpunctella colonies (unpublished data). Hemolin also may play a role as a procoagulant (Alvarez-Flores et al., 2010), and is inducible by dsRNA injection, and affects insect development and immune response against viruses (Hirai et al., 2004).

To prolong the efficacy of $B t$ formulations in the field, it is important to understand the role of gut bacteria in $B t$ toxicity. The aim of the present study was to determine the relationship of $P$. interpunctella intestinal bacteria with susceptibility to $B t$ and various parameters of the immune response.

\section{Materials and methods}


All enzymes, substrates, and chemicals were obtained from Sigma-Aldrich Chemical, S. de RL de CV (Toluca de Lerdo, Estado de México, México), unless otherwise specified.

\subsection{Bacterial formulation}

Commercial Bacillus thuringiensis (Bt) var. kurstaki HD-1, Bactospeine ${ }^{\circ}$ DF (Valent de México, Zapopan, Jalisco) containing Cry1Aa, Cry1Ab, Cry1Ac, Cry2A, and Cry2B protoxins and spores with 32,000 UI/mg potency, was used in this study.

\subsection{Insect Colony}

P. interpunctella larvae were obtained from stock cultures from the Center for Grain and Animal Health Research, Manhattan, KS, USA, and maintained at UANL. P. interpunctella larvae were reared on a cracked wheat diet (McGaughey and Beeman, 1988) at $25^{\circ} \mathrm{C} \pm 2^{\circ} \mathrm{C}, 55 \pm$ $10 \%$ relative humidity, and $16 \mathrm{~h}$ light/8h dark photoperiod. For gut bacterial assays, larvae were reared under normal artificial diet (Nuñez-Mejía et al., 2016) (Fig. S1), artificial diet (wheat agar, wheat germ, soy flour and sugar sterilized by autoclave, and vitamin solution sterilized by membrane filtration and added after artificial diet temperature was lower than $60^{\circ} \mathrm{C}$ ), and/or antibiotic treated agar-based artificial diet, where antibiotic solution was sterilized by membrane filtration and added after artificial diet temperature was lower than $60^{\circ} \mathrm{C}$. Either cereal or artificial diet treatments were assayed using individual tight-lid small plastic 47-mm diameter Petri dishes. 


\subsection{Gut bacteria eradication}

Gut bacteria were eliminated using the technique described by Broderick et al. (2006, 2010); in brief, larvae were fed a sterile artificial diet containing an antibiotic solution of 500 $\mu \mathrm{g} / \mathrm{mL}$ each rifampicin, gentamicin, penicillin, and streptomycin, which was mixed in the diet when it was liquid (at about $55^{\circ} \mathrm{C}$ ), and placed into Petri dishes to let it cool and solidify. The

aerobic/facultative bacteria present in $3^{\text {rd }}$ instar larvae gut were determined by the colony forming units (CFU) technique on LB agar medium, and analyzed by PCR using the universal 16S rRNA gene primers for bacterial amplification, as described by Frank et al. (2008).

A second method was used to eliminate bacteria from the gut. Approximately, $100 \mu \mathrm{L}$ volume of collected eggs were resuspended in $1.0 \mathrm{~mL}$ of $0.8 \%$ saline solution, and disinfected with $13 \%$ sodium hypochlorite solution (Cloralex ${ }^{\mathrm{TM}}$, Industrial Alen, Santa Catarina, N.L., MX), and diluted in distilled water to 5\% vol:vol. Eggs were soaked in this solution for $15 \mathrm{sec}$, and then rinsed by three continuous washes in $0.8 \%$ saline solution. Eggs were carefully placed on sterile diet in Petri dishes. Experiments were performed under a laminar flow cabinet to avoid microbial contamination.

\subsection{Gut bacteria identification}

P. interpunctella larvae from various diet treatments were chilled to $4{ }^{\circ} \mathrm{C}$ in refrigerator for $20 \mathrm{~min}$ and surface sterilized in 5\% commercial sodium hypochlorite diluted to a final $0.56 \%$ (Cloralex ${ }^{\mathrm{TM}}$, Industrial Allen, Santa Catarina, N.L., MX) for $15 \mathrm{sec}$. The guts of six larvae from 
each treatment were pooled and total microbial DNA was extracted with the kit Kit AxyPrep ${ }^{T M}$ Multisource Genomic DNA Miniprep Kit (Axygen, Union City, CA).

DNA extract was used as a template for PCR amplification of 16S rRNA genes using universal primers 27F 5'-AGA GTT TGA TCC TGG CTC AG-3', 1492 R 5'- TAC CTT GTT ACG ACT T-3'previously used by Frank et al. (2008). PCR was performed using Taq \& GoTM Master Mix (Promega) for a $50 \mu \mathrm{L}$ volume, with $100 \mathrm{ng}$ of template DNA, $2 \mu \mathrm{M}$ forward (27F) and reverse (1492R) primers. The thermal cycling conditions were an initial denaturation step at $94^{\circ} \mathrm{C}$ for $10 \mathrm{~min}$, followed by 35 cycles of denaturation at $94^{\circ} \mathrm{C}$ for $40 \mathrm{sec}$, annealing at $60^{\circ} \mathrm{C}$ for $40 \mathrm{sec}$, and elongation at $72^{\circ} \mathrm{C}$ for $2 \mathrm{~min}$, and a final extension at $72^{\circ} \mathrm{C}$ for $10 \mathrm{~min}$.

Amplified PCR products were analyzed on $1.0 \%$ agarose gel, purified with a Wizard® SV Gel and PCR Clean-Up System (Promega) and ligated into pGEM-T Easy (Promega) in competent E. coli TOP-10 cells. Detected plasmids were purified using the Wizard® Plus SV Minipreps DNA Purification System. Sanger sequencing was performed with standard vector M13F and M13R primers from the National Laboratory of Genomics for Biodiversity (LANGEBIO, Irapuato Mexico). Bacterial classification was performed using the Ribosomal Database Project (http://rdp.cme.msu.edu/; Wang et al., 2007).

\subsection{Bioassays}

The interaction of $B t$ (Bactospeine) and gut bacteria was evaluated using $3^{\text {rd }}$ instar larvae. Treatments included 1) larvae fed artificial diet (control), 2) larvae exposed to artificial diet containing $B t$ at the $\left.\mathrm{LC}_{50}\left(541.4 \mathrm{UI} / \mathrm{cm}^{2}, B t\right), 3\right)$ same as treatment 2 , but using artificial diet with antibiotics $(B t+\mathrm{An}), 4)$ larvae fed on diet with antibiotics for $24 \mathrm{~h}$ and subsequently exposed to 
$B t$-treatment in sterile diet with no antibiotics (Bt+An-SD), 5) larvae fed on diet with antibiotics (An), and 6) larvae fed on diet with antibiotics for $24 \mathrm{~h}$ and subsequently transferred to SD with no antibiotics (An-SD). Bt treatment was applied to the surface of the artificial diet, and if antibiotics were used in any of the six treatments, they were added to $6 \mathrm{~mL}$ of warm liquid artificial diet placed on 50 × 9 mm, tight-fit lid Falcon® sterile Petri dishes (VWR, Monterrey N.L. Mexico) (Tamez-Guerra et al., 2006). Treatments were incubated at $25^{\circ} \mathrm{C} \pm 2^{\circ} \mathrm{C}, 55 \pm 10 \%$ relative humidity, and $16 \mathrm{~h}$ light/8h dark photoperiod, until larvae from control treatment reached the pupa stage. Bioassays were done in triplicate, and percent mortality was recorded after four days.

\subsection{PO activity}

PO activity was determined according to Valadez-Lira et al. (2012). In brief, hemolymph was collected into $1.5-\mathrm{mL}$ microcentrifuge tubes and frozen at $20^{\circ} \mathrm{C}$ for $5 \mathrm{~min}$ to lyse hemocytes and release the inner-cell plasma. Samples were then thawed and centrifuged at $5000 \mathrm{rpm}$ for $1 \mathrm{~min}$ to separate the PO-containing plasma, and $5 \mu \mathrm{L}$ of plasma sample were placed in a microplate well with $195 \mu \mathrm{L}$ of $10 \mathrm{mM}$ L-3,4-dihydroxy-phenylalanine (L-DOPA), diluted in phosphate buffered saline (PBS; $137 \mathrm{mM} \mathrm{NaCl}, 2.7 \mathrm{mM} \mathrm{KCl,} 10 \mathrm{mM} \mathrm{Na} 2 \mathrm{HPO}_{4}, 1.8 \mathrm{mM} \mathrm{KH} \mathrm{PO}_{4}, \mathrm{pH}$ 7.4). Microplates were incubated in the dark at room temperature, and optical densities were read after $30 \mathrm{~min}$ at $490 \mathrm{~nm}$, using a microplate reader DTX 880 Multimode Detector® (Beckman Coulter, Inc., Fullerton, CA, USA); 1 unit/ml PO activity was defined as the amount of enzyme resulting in an increase of 0.001 absorbance units/min (Baer et al., 2009). 


\subsection{Hemocyte count}

The number of hemocytes per mililiter of hemolymph was determined using a hemocytometer. Hemolymph samples were collected by puncturing the larval proleg, and placed into $1.5 \mathrm{~mL}$ microcentrifuge tubes on ice (pooling three larvae samples for replicate), and then diluted 1:10 with ice-cooled PBS.

\subsection{Hemolin transcript detection}

Semi-quantitative RT-PCR was performed using the Improm-RT kit (Promega, Madison, Wisconsin, USA). PCR was conducted using GoTaq ${ }^{\circledR}$ Green Master Mix (Promega) and $1 \mu \mathrm{M}$ for each oligonucleotide. For the hemolin gene transcript amplification, the primers PiHemF 5'AAA TTG GAG TGC CAG CAG TT-3' and PiHemR 5'-GGG GAG TTC CCC CAT AAA TA3 were selected based on the forward and reverse sequences found in P. interpunctella AY771598. Quantification of hemolin transcript expression was normalized using the internal rps 7 rRNA gene (Fabrick et al., 2003), using as primers: 1RPS75 5'-ACA ACA AGA AGT CAA TCA TCA TCT A-3'; and 2RPS73 5'-TTG TGC TCA ATG GTG GTC TGT TG-3'. Ten microliters of the amplified sample were visualised in a $1 \%$ agarose gel and ethidium bromide stain under UV light, using a UVP trans-illuminator (VWR, Aurora, OH, USA). Semiquantitative expression was evaluated by measuring DNA band optical densities using the ImageJ version 1.46 .

\subsection{Statistical analysis}


Results were expressed as mean $\pm \mathrm{SE}$ of three replicate determinations from three independent experiments. Statistical significance was assessed by the ANOVA, $p<0.05$, and pos-hoc Tukey, using SPSS 17 (SPSS, 2008). As dependent variables, mortality percentage, number of hemocytes, and PO activity data were analyzed. As independent variables, all treatments were compared (control, SD, $B t$, An, $B t+\mathrm{An}, \mathrm{An}-\mathrm{SD}, B t+\mathrm{An}-\mathrm{SD}$ ). In addition, the semi-quantitative expression of hemolin transcript was compared to that of the rps 7 internal gene among treatments. Significant statistical differences between the groups were $p \leq 0.05$, unless otherwise stated. The results were expressed as mean $\pm \mathrm{SE}$ of three replicate determinations from three independent experiments.

\section{Results}

Since we wanted to use the $\mathrm{LD}_{50}$ of the commercial product Bactoespeine against $P$. interpunctella in our bioassays, a dose response assay was conducted. The calculated $\mathrm{LD}_{50}$ was $541.4 \mathrm{IU} / \mathrm{cm}^{2}$ (C.L. $\left.=432.65-692.35\right)$, and this amount was used in all subsequent bioassays.

A mix of antibiotics (rifampicin, gentamicin, penicillin, and streptomycin) was addded to diets to eliminate $P$. interpunctella larval gut bacteria. Larvae were allowed to feed 24 h on diets containing the antibiotics cocktail, and guts were isolated from ice-anesthetized larvae. To confirm the eradication of gut bacteria, CFU assays and bacterial 16S rRNA PCR were performed with the extracted guts from $3^{\text {rd }}$ instar larvae. Suppression of bacterial growth was observed at 250, 500, and $1000 \mu \mathrm{g} / \mathrm{mL}$ in CFU assays (Table S1), and $16 S$ rRNA PCR analysis 
indicated that bacteria were eliminated at doses equal to or greater than $100 \mu \mathrm{g} / \mathrm{mL}$ (Fig. S2).

Similarly, absence of bacteria in larvae reared under aseptic conditions (after hypochlorite treatment of eggs and rearing hatching larvae under sterile conditions) was compared by $\mathrm{CFU}$ assays and bacterial 16S rRNA PCR, with similar results (data not shown).

Based on the sequences of $16 \mathrm{~S}$ rRNA, $P$. interpunctella midgut bacteria were identified at the genus level using The Ribosomal Database Project (http://rdp.cme.msu.edu/; Wang et al., 2007). The results included sequences related to eight different genres (Table 1). The majority of the sequences corresponding to the phylum Proteobacteria (74.4\%), Firmicutes (9\%) and Actinobacteria (14\%). From the Proteobacteria, 38\% corresponded to the $\gamma$-proteobacteria, $20 \%$ to $\beta$-proteobacterias, and $17 \%$ to $\alpha$-proteobacterias. Regarding the gut bacterial diversity classifiable at genera level, species of Pseudomonas were the major genera (34\%), followed by Achromobacter (19\%), Methylobacterium (16\%), and Propionibacterium (12\%).

\subsection{Bt susceptibility after antibiotic exposure or sterile rearing conditions.}

Bioassays of $3^{\text {rd }}$ instar $P$. interpunctella larvae exposed to $B t$ at the $\mathrm{LD}_{50}$ resulted in $60 \%$ mortality under expected confidence limits (Fig. 1A). However, treatment with the same Bt dose, but in diet mixed with antibiotics $(B t+A n)$, resulted in less than $10 \%$ mortality. Significant differences $(p<0.001)$ in larvae mortality were observed between $B t$ treatment alone and unexposed control, as well as all treatments with the antibiotics mixture $(p<0.05)$. Larvae fed on antibiotic-treated diet, with or without $B t(\mathrm{An}, B t+\mathrm{An})$ or in presterilized rearing conditions (Bt+An-SD), resulted in significantly lower mortality compared with larvae under normal rearing 
(Bt) conditions ( $\mathrm{F}=20.3_{5,12} ; P<0.001$, Tukey HSD, $\left.\alpha=0.05\right)$, and mortality from these treatments were similar to that of the unexposed control. Furthermore, $B t$ susceptibility was significantly higher among normal rearing condition larvae (53.3\% mortality), compared with larvae from hypochlorite-sterilized eggs and reared under sterile conditions (14.4\% mortality, Fig. 1B).

\subsection{Hemocyte count}

$B t$ treatment of $3^{\text {rd }}$ instar P. interpunctella larvae resulted in significantly lower counts of hemocytes from the hemolymph $\left(7.16 \mathrm{Hem} \times 10^{6} / \mathrm{mL}\right)$ compared with treatments that were designed to lower the amount of gut bacteria (An, An-SD, Bt+An, Bt+An-SD), and the count was slightly lower than that of the untreated control (1.83 Hem x 107/mL) (Fig. 2A). Overall, insects reared with antibiotics or under sterile rearing conditions had increased numbers of hemocytes compared to those on control diet. The most significantly $(p<0.001)$ high hemocyte count was detected in the hemolymph of $B t+$ An-treated larvae $\left(4.72 \mathrm{Hem} \times 10^{7} / \mathrm{mL}\right)\left(\mathrm{F}_{5,12}=10.64, P\right.$ $<0.001$ ). When $P$. interpunctella larvae were reared under sterile conditions (SD), larval hemolymph had higher numbers of hemocytes $\left(1.27 \mathrm{Hem} \times 10^{8} / \mathrm{mL}\right)$ than larvae reared under normal conditions (3.83 Hem x 107/mL) (Fig. 2B), or any other treatment (Fig. 2A).

\subsection{Phenoloxidase activity}

In contrast to the hemocyte count observations, the highest PO activity was observed in untreated control larvae and larvae reared on antibiotic treated diet, without or with $B t$ (An, 
Bt+An) (Fig. 3A). P. interpunctella larvae reared under normal conditions had the highest PO

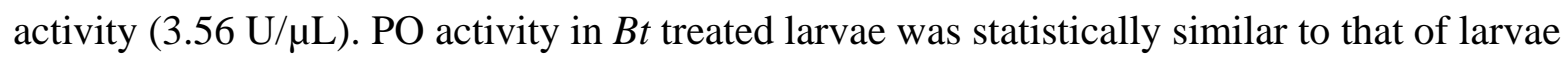
reared on sterile diet, and significantly less than that of the control and $B t+$ An larvae. The lowest PO activity was detected among $B t+\mathrm{An}-\mathrm{SD}$ treated larvae and was significantly different from all other treatments $\left(\mathrm{F}_{5,12}=20.35, p<0.001\right)$. PO activity in larvae fed control diet was significantly higher than that of larvae reared under sterile conditions and fed $B t$-treated diet (Bt-SD) (1.07 $\mathrm{U} / \mu \mathrm{L})\left(\mathrm{F}_{2,6}=7.089 ; P=0.026\right)($ Fig. 3B).

\subsection{Hemolin transcript detection}

The effect of treatments on the expression of the $P$. interpunctella immune response gene hemolin was detected by RT-PCR. The relative density of the PCR product was calculated by dividing the hemolin density from each sample/treatment by the density of $r p s 7$ (used as endogenous control gene and compared by densitometry) (Tan and Ng, 2008; Gassmann et al., 2009). Hemolin expression was the lowest in larvae fed on antibiotic-treated diet (An, An-SD) (Fig. 4A). Expression of hemolin was also suppressed in Bt-treated larvae, but was slightly increased in larvae fed $B t$ and the antibiotic mixture $(B t+\mathrm{An})$, and further increased when larvae were pretreated with the antibiotic mixture and then exposed to $B t(B t+\mathrm{An}-\mathrm{SD})$. Under sterile conditions, hemolin expression was decreased compared to control with or without Bt (Fig. 4B). However, these larvae did not molt to the pupal stage, and remained as $5^{\text {th }}$ instar for more than one month. 


\section{Discussion}

Since their discovery, bioinsecticides based on $B t$ have demonstrated targeted insect control with minimal environmental impact. Understanding the biology of insect pests, as well as interactions with pathogens and microbiota, can help to enhance their effect within these interactions. In the present study, methodology similar to previous studies was used to evaluate the effect of gut bacteria on the response to Bt. However, in addition to mortality; we also evaluated other bacterial responses in larvae, such as the number of hemocytes and PO activity in the larval hemolymph, as well as the relative expression of the hemolin gene.

All $3^{\text {rd }}$ instar P. interpunctella larvae were fed a diet containing an antibiotic cocktail $24 \mathrm{~h}$ prior to $B t$ administration. Confirmation of the reduction of gut bacteria was evaluated by combining the CFU test with PCR amplification of 16S rRNA universal primers for bacteria. Regardless of the method of bacterial-clearing, larvae without gut bacteria were significantly less susceptible to $B t$. Thus, removal of bacteria from the larval gut contributed to a significantly decreased susceptibility to $B t$.

Streptomycin inhibited Bt-toxicity in Bt-resistant diamondback moth (Plutella xylostella L.), but not in Bt-susceptible insects, and this effect was only demonstrated with $B t$ subsp. kurstaki, but not with Bt subsp. aizawai (Liu et al., 1998). Helicoverpa armigera (Hübner) larvae feeding on a diet with the same antibiotic cocktail as reported by Broderick et al. (2006, 2010) did not develop resistance to Cry1Ab or Cry1Ac after transgenerational Bt exposure, but mortality was reduced $30 \%$ in the F3 generation of insects reared on antibiotics-free diet and exposed to Bt (Paramasiva et al., 2014). However, gut bacteria affected Bt Cry1Ac and formulation toxicity against $H$. armigera larvae (Visweshwar et al., 2015). 
After exposing $P$. interpunctella to the antibiotics mixture and the $\mathrm{LC}_{50}$ of the $B t$ formulation, larval mortality was significantly reduced compared with a control without antibiotics. However, the cellular immune response was affected by the antibiotic treatment, and the number of hemocytes in larval hemolymph from antibiotic treated larvae fed $B t$ was significantly higher compared with that of untreated control, in agreement with Frankenhuyzen et al. (2010). These changes were not solely related to $B t$ (spores and toxins present in Bactospine product), but by the combined $B t$ and antibiotic effect in the insect, since the number of hemocytes also was significantly higher than larvae fed Bt only. In addition, significantly higher numbers of hemocytes were also found in larvae hatching from sterilized eggs. The reduction of hemocytes after $B t$ exposure may be the result of micro-aggregations, or by an effect on hemocyte differentiation in response to $B t$.

In contrast, larvae fed antibiotic-treated diet and reared under normal conditions (An and $B t+$ An treatments) resulted in $\mathrm{PO}$ activity levels similar to those of untreated control, whereas $B t$ alone and An-SD treatments resulted in reduced PO activity. Moreover, insects pretreated with antibiotics and then exposed to $B t(B t+\mathrm{An}-\mathrm{SD}$ treatment) had the lowest PO activity among all treatments, which also was observed if eggs were presterilized and larvae were exposed to $B t$. The contrasting effect observed between hemocytes (cellular response) and PO activity (humoral response) (James and $\mathrm{Xu}, 2012$ ) may be attributed to the physiological cost of immune regulation, similar to that reported in other Lepidoptera exposed to Bt (Caron and Myers, 2008; Gassmann et al., 2009a, b), their toxins (Carrière et al., 2010; Tamez-Guerra, 2010) or nonpathogenic bacteria (Freitak et al., 2007).

Our results indicated that the expression of hemolin was lower among $B t$-treated larvae compared with untreated control. Similarly, hemolin expression was also downregulated in 
larvae exposed to antibiotics. These results were consistent with those reported by Wan et al. (2013) in Bombyx mori L., where hemolin expression was reduced by most Gram-positive (such as $B t$ ) and negative bacteria (such as Escherichia coli). Bacterial infections and/or $B t$ exposure may cause differential interspecies responses. The ability of $B t$ to reduce the basal immune response in insects has been previously described (Dalhammar and Steiner, 1984; Fedhila et al., 2002); the effect has been related to an exoprotease A inhibitor, which degrades the antimicrobial peptides attacins and cecropins.

In $P$. interpunctella larvae reared from sterilized eggs, hemolin gene expression was not detected and larvae did not progress to pupae, but remained as $5^{\text {th }}$ instar for more than one month. These data are in agreement with the observation that hemolin is involved in the metamorphosis process from larva to pupa (Aye et al., 2004; Bettencourt et al., 2000). Our data suggested that gut bacteria may influence the expression of hemolin. Yu and Kanost (1999) demonstrated that hemolin is primarily expressed in the fat body and gut epithelial tissue, and therefore expression may be influenced by gut bacteria (Freitak et al., 2007; Noverr and Huffnagle, 2004). In fact, bacteria, rather than viral infections, upregulate hemolin (Tereniu et al., 200s9; Aye et al., 2004; Roxstrom-Lindquist et al., 2005).

It is important to note that the method of bacterial elimination (by larval feeding of antibiotics or by presterilization of eggs) resulted in different immune responses. The number of hemocytes was an order of magnitude higher in insects presterilized as eggs and reared on a sterile diet, compared to larvae fed antibiotic-treated diet. Conversely, the phenoloxidase activity was lower in presterilized insects reared on sterile diet compared to larvae fed antibiotic treated diet, especially when in addition larvae were exposed to Bt. We speculate that immune 
responses, as well as other biological traits, are greatly altered in larvae deprived of gut bacteria from the embryo stage, and these observations require further study.

The gut bacteria of $P$. interpunctella do not resemble reports of bacterial communities in other lepidopteran species. For instance, in Helicoverpa armígera (Hübner) and Spodoptera littoralis (Boisduval), the highest bacterial percentage reported belonged to Clostridium and Enterococcus genus, with $42.2 \%$ and $42.3 \%$, respectively (Tang et al., 2012). In Pieris rapae L., most of detected bacteria belonged to Methylobacteria (Robinson et al., 2010), found in our study in P. interpunctella was only $16 \%$ of total bacteria, whereas $9 \%$ of the sequenced clones were identified as Propionibacterium acnes. This bacterium has been also reported in $S$. littoralis and H. armigera (Tang et al., 2012), and was also reported by Ranjith et al. (2016) as one of the largest species detected in H. armigera. P. acnes reportedly produce lactic acid, propionic acid and acetic acid from glucose (Piveteau, 1999). These compounds may reduce susceptibility to $B t$ by lowering the $\mathrm{pH}$ in the gut environment, affecting Cry toxin solubility, although this hypothesis remains to be tested.

In this study, the most abundant bacteria belonged to the Pseudomonas genus, with $35 \%$, and phylogenetically identified as Pseudomonas stutzeri, species reported to have denitrifying activity and capable of carbon tetrachloride degradation after warehouse insecticide was used (Sepulveda-Torres et al., 1999). This could explain how the bacterium colonized the gut of an insect pest of warehouse products. In addition, $P$. stutzeri has been isolated from the beetle Costelytra zealandica gut (Ray et al., 2007) and identified by biochemical tests in the lepidopteran Cydia pomonella L. (Ertürk and Demirba 2006) as well as in Rothschildia lebeau pupae (Pinto-Tomás et al. 2007). 
In summary, we found that $B t$ toxicity was significantly decreased when $P$. interpunctella larvae were deprived of gut bacteria. These observations have important implications in how Bt toxins kill lepidopteran larvae and may be exploited for modifications of $B t$ toxin pest management strategies. In addition, since the lack of gut bacteria inhibits hemolin expression and prevents the P. interpunctella pupation process, bacterial content may be manipulated to potentially increase toxicity in this important lepidopteran pest as a new method of pest control.

\section{Acknowledgments}

This study was supported by Laboratorio de Inmunología y Virología (FCB-UANL), CONACyT scholarship 377304 to AAOF and PAICYT-UANL grant No. CA760-11 to PTG. Mention of trade names or commercial products in this publication is solely for the purpose of providing specific information and does not imply recommendation or endorsement by the U.S.

Department of Agriculture. USDA is an equal opportunity provider and employer.

Author Contributions: Main text paragraph.

Conflicts of Interest: The authors declare that there are no conflicts of interest.

\section{References}


Alvarez-Flores, M.P., Furlin, D., Ramos, O.H., Balan, A., Konno, K., Chudzinski-Tavassi, A.M. 2011. Losac, the first hemolin that exhibits procogulant activity through selective factor X proteolytic activation. J. Biol. Chem. 286, 6918-6928. DOI: 10.1074/jbc.M110.167718

Aye, T., Lee, K.Y., Kwon, Y.J. 2004. Cloning of immune protein hemolin cDNA from the Indian meal moth, Plodia interpunctella, and its high induction during development and by bacterial challenge. Entomol. Res. 34, 269-275. DOI:10.1111/j.1748-5967.2004.tb00122.x

Bettencourt, R., Assefa-Redda, Y., Faye, I. 2000. The insect immune protein hemolin is expressed during oogenesis and embryogenesis. Mechanisms of Development. 95, 301304. DOI:10.1016/S0925-4773(00)00359-2

Baer, B., Eubel, H., Taylor, N.L., O’Toole, N., Millar, A.H. 2009. Insights into female sperm storage from the spermathecal fluid proteome of the honeybee Apis mellifera. Genome Biol. 10(6), R67. DOI:10.1186/gb-2009-10-6-r67

Broderick, N.A., Raffa, K.F., Handelsman, J. 2006. Midgut bacteria required for Bacillus thuringiensis insecticidal activity. PNAS-USA. 103,15196-15199. DOI:10.1073/pnas.0604865103

Broderick, NA, Raffa KF, Handelsman J. 2010. Chemical modulators of the innate immune response alter gypsy moth larval susceptibility to Bacillus thuringiensis. BMC Microbiol. 10(129). DOI: 10.1186/1471-2180-10-129

Caccia, S., Di Lelio, I., La Storia, A., Marinelli, A., Varricchio, P., Franzetti, E., Banyuls, N., Tettamanti, G., Casartelli, M., Giordana, B., Ferre, J., Gigliotti, S., Ercolini, D., Pennacchio, F. 2016. Midgut microbiota and host immunocompetence underlie Bacillus thuringiensis killing mechanism. PNAS, 113, 9486-9491. DOI:

http://doi.org/10.1073/pnas.1521741113 
Carrière, Y., Crowder, D.W., Tabashnik, B.E. 2010. Evolutionary ecology of insect adaptation to Bt crops. Evol. Appl. 3, 561-573. DOI: 10.1111/j.1752-4571.2010.00129.x

Caron, V., Myers, J.H. 2008. Positive association between resistance to Bacillus thuringiensis and overwintering survival of cabbage loopers, Trichoplusia ni (Lepidoptera: Noctuidae). Bull. Entomol. Res. 98, 317-322. DOI:10.1017/S0007485307005597.

Dalhammar, G., Steiner, H. 1984. Characterization of inhibitor A, a protease from Bacillus thuringiensis which degrades attacins and cecropins, two classes of antibacterial proteins in insects. Eur. J. Biochem. 139,247-252. DOI:10.1111/j.1432-1033.1984.tb08000.x

Dillon, R.J., Dillon, V.M. 2004. The gut bacteria of insects: nonpathogenic interactions. Annu. Rev. Entomol. 49, 71-92. DOI: 10.1146/annurev.ento.49.061802.123416

Eleftherianos, L., Atri, J., Accetta, J., Castillo, J.C. 2013. Endosymbiotic bacteria in insects: Guardians of the immune system? Front. Physiol. 4, 1-10. http://doi.org/10.3389/fphys.2013.00046.

Ericsson, J.D., Janmaat, A.F., Lowenberger, C., Myers, J.H. 2009. Is decreased generalized immunity a cost of Bt resistance in cabbage loopers Trichoplusia ni?. J. Invertebr. Pathol. 100,61-67. DOI:10.1016/J.JIP.2008.10.007

Ertürk, O., Demirba, Z. 2006. Studies on bacterial flora and biological control agent of Cydia pomonella L. (Lepidoptera: Tortricidae). African J. Biotechnol. 5, 2081-2085. DOI: 10.4314/ajb.v5i22.55972

Fabrick, J. A., J. E. Baker, and M. R. Kanost. 2003. cDNA cloning, purification, properties, and function of a $\beta-1,3$-glucan recognition protein from a pyralid moth, Plodia interpunctella. Insect Biochem. Mol. Biology. 33,579-594 
Fedhila, S., Nel, P., Lereclus, D. 2002. The InhA2 metalloprotease of Bacillus thuringiensis strain 407 is required for pathogenicity in insects infected via the oral route. J. Bacteriol. 184,3296-3304. DOI:10.1128/JB.184.12.3296-3304.2002

Frank, J.A., Reich, C.I., Sharma, S., Weisbaum, J.S., Wilson, B.A., Olsen, G.J. 2008. Critical evaluation of two primers commonly used for amplification of bacterial 16S rRNA genes. Appl. Environ. Microbiol. 74, 2461-2470. DOI:10.1128/AEM.02272-07

Frankenhuyzen, K., Liu, Y., Tonon, A. 2010. Interactions between Bacillus thuringiensis subsp. kurstaki HD-1 and midgut bacteria in larvae of gypsy moth and spruce budworm. J. Invertebr. Pathol. 103,124-31. DOI:10.1016/j.jip.2009.12.008.

Freitak, D., Wheat, C.W., Heckel, D.G., Vogel, H. 2007. Immune system responses and fitness costs associated with consumption of bacteria in larvae of Trichoplusia ni. BMC Biol. 5(56). DOI:10.1186/1741-7007-5-56

Gassmann, M., Grenacher, B., Rohde, B., Vogel, J. 2009a. Quantifying western blots: pitfalls of densitometry. Electrophoresis. 30,1845-1855. DOI:10.1002/elps.200800720

Gassmann, A.J., Fabrick, J.A., Sisterson, M.S., Hannon, E.R., Stock, S.P., Carriére, Y., Tabashnik, B.E. 2009b. Effects of pink bollworm resistance to Bacillus thuringiensis on phenoloxidase activity and susceptibility to entomopathogenic nematodes. J. Econ. Entomol. 102,1224-1232. DOI:http://dx.doi.org/10.1603/029.102.0348

Hirai, M., Terenius, O., Li, W., Faye, I. 2004. Baculovirus and dsRNA induce Hemolin, but no antibacterial activity, in Antheraea pernyi. Insect Molecular Biology, 13(4): 399-405. DOI:10.1111/j.0962-1075.2004.00497.x

James, R.R., Xu, J. 2012. Mechanisms by which pesticides affect insect immunity. J. Invertebr. Pathol. 109,175-182. DOI:10.1016/j.jip.2011.12.005. 
Johnston, P.R., Crickmore, N. 2009. Gut bacteria are not required for the insecticidal activity of Bacillus thuringiensis toward the tobacco hornworm, Manduca sexta. Applied and Environmental Microbiology, 75,5094-5099. http://dx.doi.org/10.1128/AEM.00966-09

Kim, C-H., Park, J-W., Ha, N-C, Kang, H.J., Lee, B.L. 2008. Innate immune response in insects: recognition of bacterial peptidoglycan and amplification of its recognition signal. BMB reports, 41,93-101. DOI:10.5483/BMBRep.2008.41.2.093.

Lavine, M.D., Strand, M.R. 2002. Insect hemocytes and their role in immunity. Insect Biochem. Mol. Biol. 32,1295-1309. DOI:10.1016/S0965-1748(02)00092-9

Liu, Y.B., Tabashnik, B.E., Moar, W.J., Smith, R.A. 1998. Synergism between Bacillus thuringiensis spores and toxins against resistant and susceptible diamondback moths (Plutella xylostella). Appl. Environ. Microbiol. 64,1385-1389. http://aem.asm.org/content/64/4/1385.short

McGaughey, W.H., Beeman, R.W. 1988. Resistance to Bacillus thuringiensis in colonies of Indian meal moth and almond moth (Lepidoptera: Pyralidae). J. Econ. Entomol. 81,28-33. DOI:10.1093/jee/81.1.28

Mohandass, S., Arthurb, F.H., Zhuc, K.Y., Throneb, J.E. 2007. Biology and management of Plodia interpunctella (Lepidoptera: Pyralidae) in stored products. J. Econ. Entomol. 43,302-311. DOI:10.1016/J.JSPR.2006.08.002

Noverr, M.C., Huffnagle, G.B. 2004. Does the microbiota regulate immune responses outside the gut?. Trends Microbiol. 12,562-568. doi:10.1016/j.tim.2004.10.008

Nuñez-Mejía, G., Valadez-Lira, J.A., Gomez-Flores, R., Rodríguez-Padilla, C., Tamez-Guerra, P. 2016. Trichoplusia ni (Lepidoptera: Noctuidae) survival, immune response, and gut 
bacteria changes after exposure to Azadirachta indica (Sapindales: Meliaceae) volatiles. Flo. Entomol. 99,12-20. http://dx.doi.org/10.1653/024.099.0104

Oppert, B., Kramer, K.J., Beeman, R.W., Johnson, D., McGaughey, W.H. 1997. Proteinasemediated resistance to Bacillus thuringiensis insecticidal toxins. J. Biol. Chem. 272, 23473-23476. DOI:10.1074/jbc.272.38.23473

Oppert, B, Kramer, K.J., Johnson, D.E., Upton, S.J., McGaughey, W.H. 1996. Luminal proteinases from Plodia interpunctella and the hydrolysis of Bacillus thuringiensis CryIA(c) protoxin. Insect Biochem. Mol. Biol. 26,571-583. DOI:10.1016/S09651748(96)00013-6

Paramasiva, I, Sharma, H.C., Krishnayya, P.V. 2014. Antibiotics influence the toxicity of the delta endotoxins of Bacillus thuringiensis towards the cotton bollworm, Helicoverpa armigera. BMC Microbiol. 14(1),17. http://doi.org/10.1186/1471-2180-14-200

Pinto-Tomás, A., Uribe-Lorío, L., Blanco, J., Fontecha, G., Rodríguez, C., Mora, M., Janzen, D., Chavarría, F., Díaz, J., Sittenfeld, A. 2007. Actividades enzimáticas en aislamientos bacterianos de tractos digestivos de larvas y del contenido de pupas de Automeris zugana y Rothschildia lebeau (Lepidoptera: Saturniidae). Rev. Biol. Trop. 55, 401-415.

DOI: http://dx.doi.org/10.15517/rbt.v55i2.6020

Piveteau, P. 1999. Metabolism of lactate and sugars by dairy propionibacteria: A review. Lait. 79, 23-41. DOI: 10.1051/lait:199912

Ranjith, M.T., ManiChellappan, Harish, E.R., Girija D., Nazeem, P.A. 2016. Bacterial communities associated with the gut of tomato fruit borer, Helicoverpa armigera (Hübner) (Lepidoptera: Noctuidae) based on Illumina Next-Generation Sequencing. Journal of AsiaPacific Entomology, (19)2: 333-340. http://dx.doi.org/10.1016/j.aspen.2016.03.007 
Ray, J.L., Andersen, H.K., Young, S., Nielsen, K.M., O'Callaghan, M. 2007. An assessment of the potential of herbivorous insect gut bacteria to develop competence for natural transformation. Environ. Biosafety Res. 6, 135-147. DOI:10.1051/ebr:2007032

Robinson, C.J., Schloss, P., Ramos, Y., Raffa, K.F., Handelsman, J. 2010. Robustness of the bacterial community in the cabbage white butterfly larval midgut. Microbial Ecol. 59, 199-

211. DOI: $10.1007 / \mathrm{s} 00248-009-9595-8$

Roxstrom-Lindquist, K, Assefaw-Redda Y, Rosinska K, Faye I. 2005. 20-Hydroxy-ecdysone indirectly regulates hemolin gene expression in Hyalophora cecropia. Insect Mol. Biol. 14, 645-652. DOI:10.1111/j.1365-2583.2005.00593.x

Sepulveda-Torres, L., Rajendran, N. Dybas, M.J., Criddle, C.S. 1999. Generation and initial characterization of Pseudomonas stutzeri KC mutants with impaired ability to degrade carbon tetrachloride. Arch. Microbiol. 171, 424-429. DOI:10.1007/s002030050729

SPSS. 2008. Version 17.0. SPSS Inc., an IBM Company. Chicago, Illinois

Tamez-Guerra, P. 2010. A review of U.S. and Mexican cooperation to develop insect resistance management and monitoring methods for surveying transgenic crops expressing Bacillus thuringiensis proteins: 2003 to 2010. Southwest. Entomol. 35,373-382.

Tamez-Guerra, P., Damas, G., Iracheta, M.M., Oppert, B., Gomez-Flores, R., Rodríguez-Padilla, C. 2006. Differences in susceptibility and physiological fitness of Mexican field Trichoplusia ni strains exposed to Bacillus thuringiensis. J. Econ. Entomol. 99,937-945. DOI:10.1093/jee/99.3.937

Tamez-Guerra, P., Valadez-Lira, J.A., Alcocer-González, J.M., Oppert, B., Gomez-Flores, R., Tamez-Guerra, R.S., Rodríguez-Padilla, C. 2008. Detection of genes encoding 
antimicrobial peptides in Mexican strains of Trichoplusia ni (Hübner) exposed to Bacillus thuringiensis. J. Invertebr. Pathol. 98,218-227. DOI:10.1016/j.jip.2008.02.008

Tan, H.Y., Ng, T.W. 2008. Accurate step wedge calibration for densitometry of electrophoresis gels. Optics Comm. 281,3013-3017. DOI:10.1016/j.optcom.2008.01.012

Tang, X., Freitak, D., Vogel, H., Ping, L., Shao, Y., Cordero, E.A., Andersen, G., Westermann, M.,. Heckel, D.G., Boland, W. 2012. Complexity and variability of gut commensal microbiota in polyphagous lepidopteran larvae. PloS one, 7(7): e36978. http://dx.doi.org/10.1371/journal.pone.0036978

Terenius, O., Popham, H.J.R., Shelby, K.S. 2009. Bacterial, but not baculoviral infections stimulate Hemolin expression in noctuid moths. Dev. Comp. Immunol. 33,1176-1185. DOI:10.1016/j.dci.2009.06.009.

Valadez-Lira, J.A., Alcocer-Gonzalez, J.M., Damas, G., Nuñez-Mejía, G., Oppert, B., Rodriguez-Padilla, C., Tamez-Guerra, P. 2012. Comparative evaluation of phenoloxidase activity in different larval stages of four lepidopteran pests after exposure to Bacillus thuringiensis. J. Insect Sci. 12.80. DOI:10.1673/031.012.8001.

Visweshwar, R., Sharma, H.C., Akbar, S.M.D., Sreeramulu, K. 2015. Elimination of gut microbes with antibiotics confers resistance to Bacillus thuringiensis toxin proteins in Helicoverpa armigera (Hübner). Appl. Biochem. Biotechnol. 177,1621-1637. DOI:10.1051/lait:199912

Vizioli, J, Salzet, M. 2002. Antimicrobial peptides from animals: focus on invertebrates. Trends Pharmacol. Sci. 23,494-496. DOI:10.1016/S0165-6147(02)02105-3

Wan, J., Zhou, X., Zhou, X. 2013. A review of innate immunity of silkworm, Bombyx mori. African J. Agr. Res. 8,2319-2325. DOI: 10.5897/AJARx11.079 
Wang, Q, G. M. Garrity, J. M. Tiedje, and J. R. Cole. 2007. Naïve Bayesian classifier for rapid assignment of rRNA sequences into the new bacterial taxonomy. Appl. Environ. Microbiol. 73, 5261-5267. DOI: 10.1128/AEM.00062-07

Yu, X.Q., Kanost, M.R. 1999. Developmental expression of Manduca sexta hemolin. Arch. Insect Biochem. Physiol. 42.198-212. DOI:10.1002/(SICI)15206327(199911)42:3<198::AID-ARCH4>3.0.CO;2-G 
Table 1. Bacterial species identified in guts of Plodia interpunctella larvae feeding on artificial diet, identified at the genus level using 16S rRNA primers. ${ }^{1}$

\begin{tabular}{|c|c|c|c|}
\hline Treatments & Control & $\begin{array}{l}\text { With antibiotics } \\
\text { cocktail }\end{array}$ & $\begin{array}{l}\text { Under sterile rearing } \\
\text { conditions }\end{array}$ \\
\hline $\begin{array}{l}\text { Bacterial species } \\
\text { detected }\end{array}$ & $\begin{array}{l}\text { Bacillus sp. } \\
\text { Methylobacterium sp. } \\
\text { Parapusillimonas sp. } \\
\text { Achromobacter sp. } \\
\text { Stenotrophomonas sp. } \\
\text { Pseudomonas sp. } \\
\text { Propionibacterium sp. } \\
\text { Corynebacterium sp. }\end{array}$ & none detected & none detected \\
\hline
\end{tabular}

\footnotetext{
${ }^{1}$ Bacterial classification was with the Ribosomal Database Project (http://rdp.cme.msu.edu/;
}

Wang et al., 2007) 


\section{Figure legends}

Figure 1. Mortality of $3^{\text {rd }}$ instar Plodia interpunctella larvae fed on treated or untreated agarbased diet. A) Control: untreated larvae; $B t$ : larvae exposed to Bt only; $B t+A n$ : larvae exposed to $B t$ and antibiotics; $B t+A n-S D$ : larvae exposed to antibiotics for $24 \mathrm{~h}$ and subsequently exposed to Bt only; An: larvae exposed to antibiotics only; An-SD: larvae exposed to antibiotics for $24 \mathrm{~h}$ and subsequently transferred to untreated diet. B) Control: untreated larvae; Bt: larvae exposed to Bt only; Bt-SD: larvae from hypochlorite sterilized eggs and reared under sterile conditions and exposed to antibiotics for $24 \mathrm{~h}$ and subsequently exposed to $\mathrm{Bt}$ only. Bars indicate S.E., and different letters above each column indicate statistical significance by Tukey HSD, $\alpha=0.05$.

Figure 2. Effects of different treatments on hemocytes from hemolymph of $3^{\text {rd }}$ instar Plodia interpunctella larvae reared on agar-based diet. A) Larvae reared under normal conditions (see treatment information in Fig. 1A); B) Larvae reared under sterile (SD) conditions (see treatment information in Fig. 1B). Bars indicate S.E., and different letters above each column indicate significance by Tukey HSD, $\alpha=0.05$.

Figure 3. Effects of different treatments on phenoloxidase activity $(\mathrm{U} / \mu \mathrm{L})$ from hemolymph of $3^{\text {rd }}$ instar Plodia interpunctella larvae reared on agar-based diet. A) Under normal conditions (see treatments information in Fig. 1A); B) Under sterile (SD) conditions (see treatments information in Fig. 1B). Bars indicate S.E., and different letters above each column indicate significance by Tukey HSD, $\alpha=0.05$. 
Figure 4. Effects of different treatments on hemolin detection from the gut of Plodia interpunctella $3^{\text {rd }}$ instar larvae. A) Larvae reared under normal conditions (see treatments information in Fig. 1A); B) Larvae reared under normal (Bt) or sterile (Bt-SD) conditions (see treatments detail in Fig. 1B). 
Figure 1.

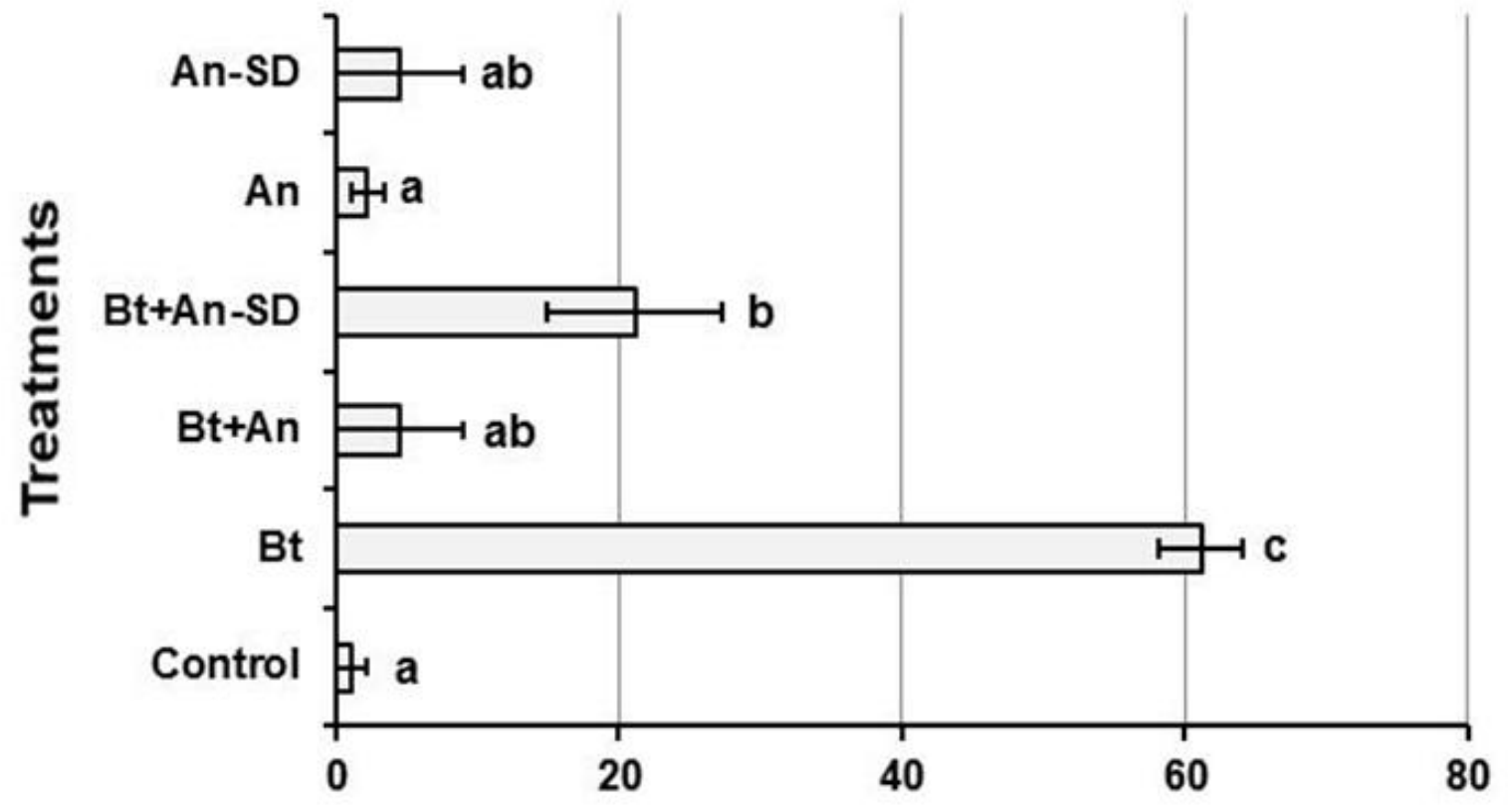

A

Plodia interpunctella $3^{\text {rd }}$ instar larvae mortality (\%)

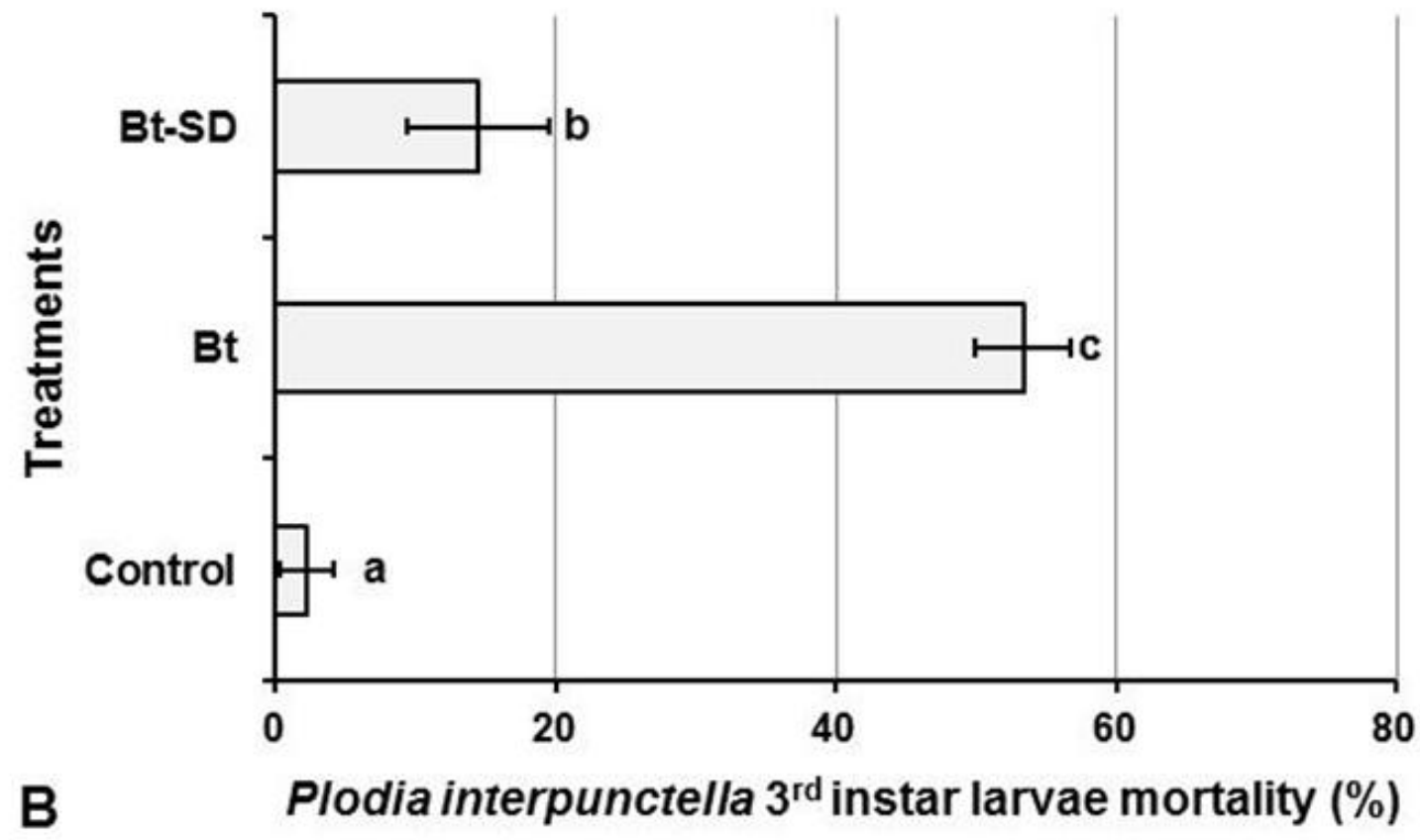


Figure 2
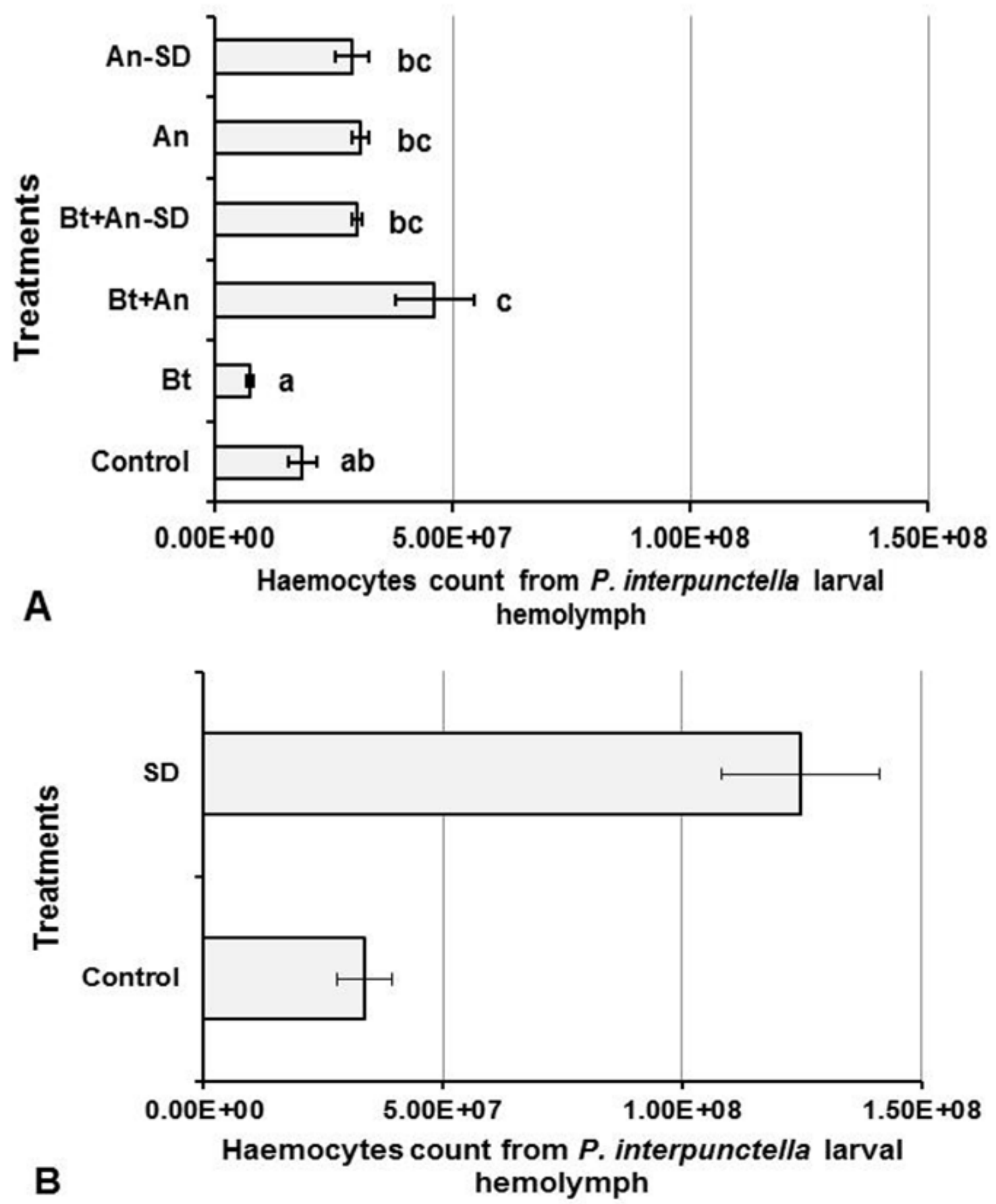
Figure 3

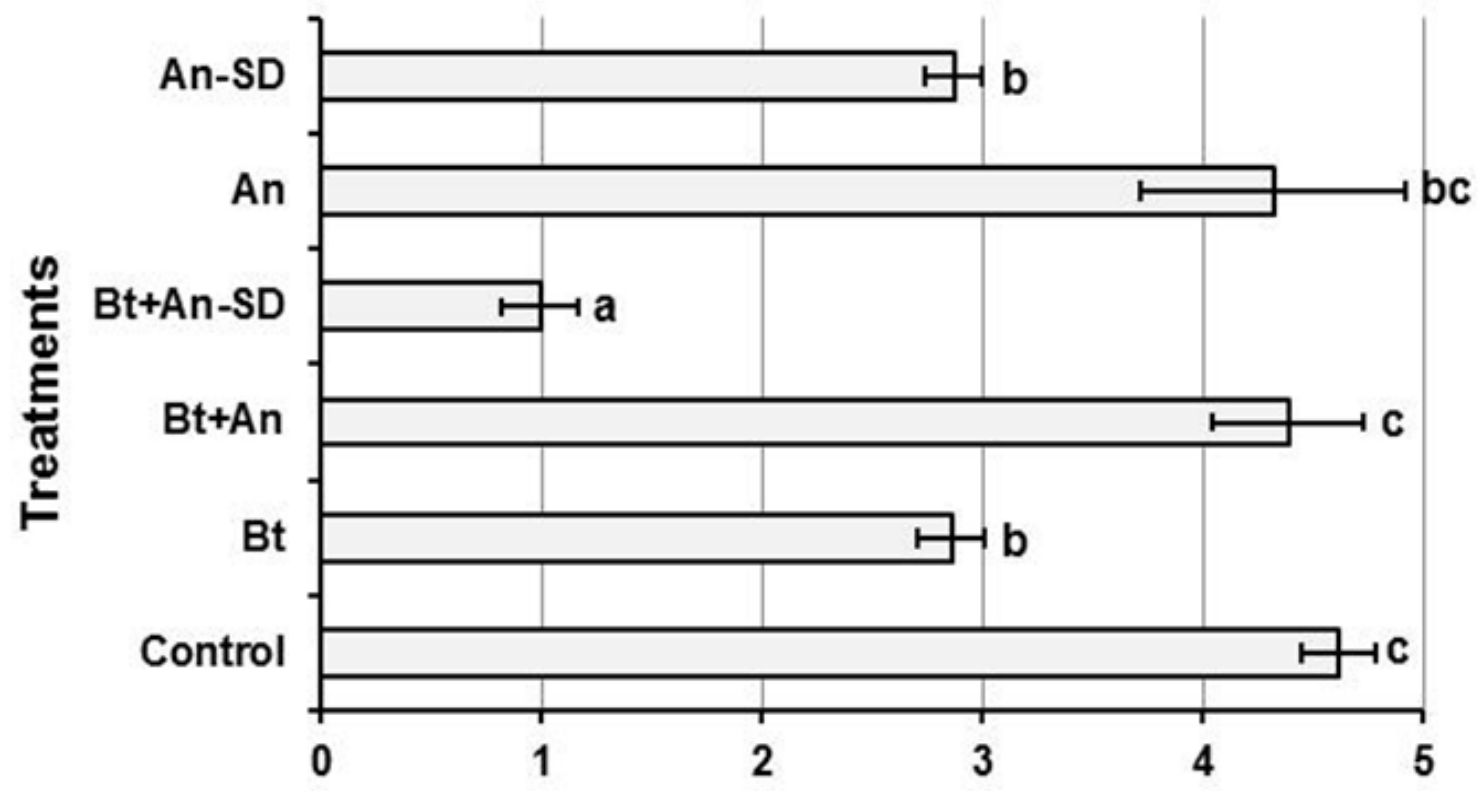

A

Phenoloxidase activity $(\mathrm{U} / \mu \mathrm{L})$ from $P$. interpunctella larval hemolymph

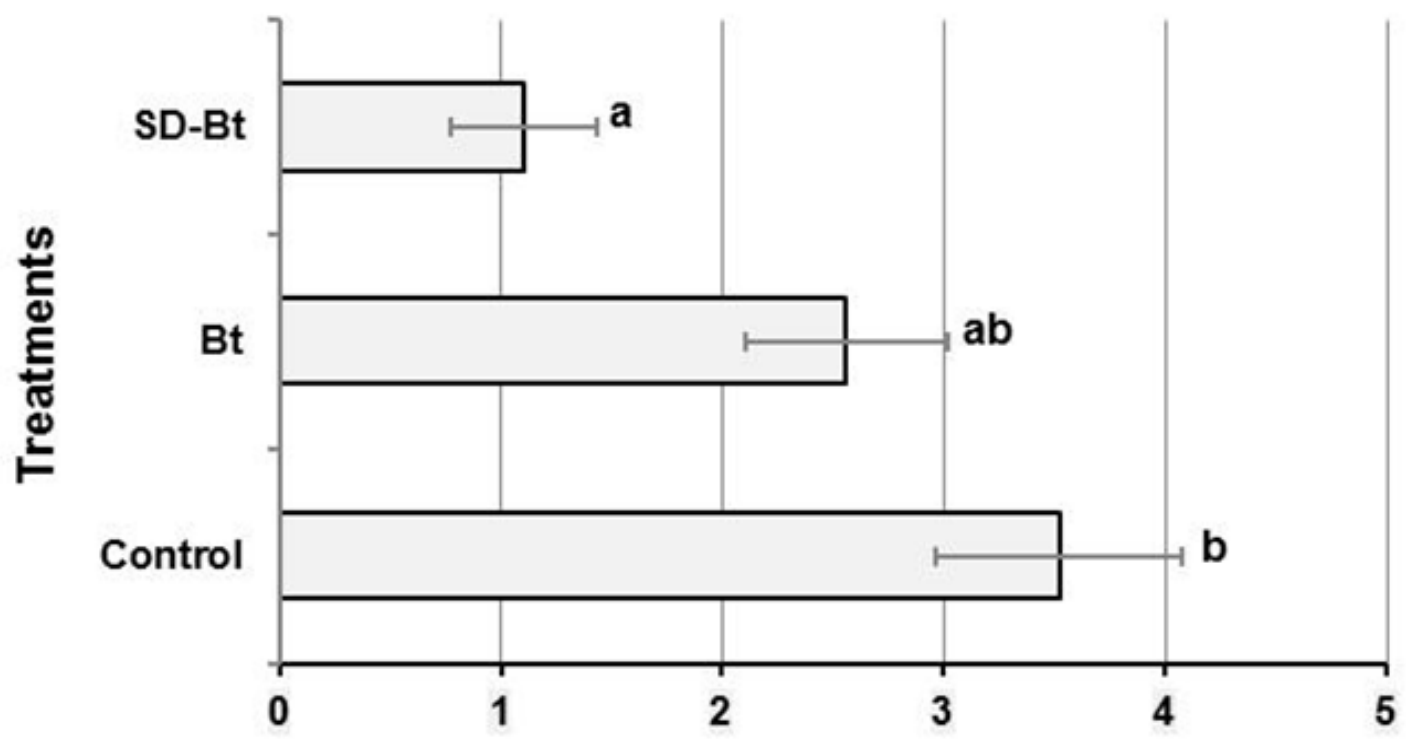

B

Phenoloxidase activity $(\mathrm{U} / \mu \mathrm{L})$ from $P$. interpunctella larval hemolymph 
Figure 4
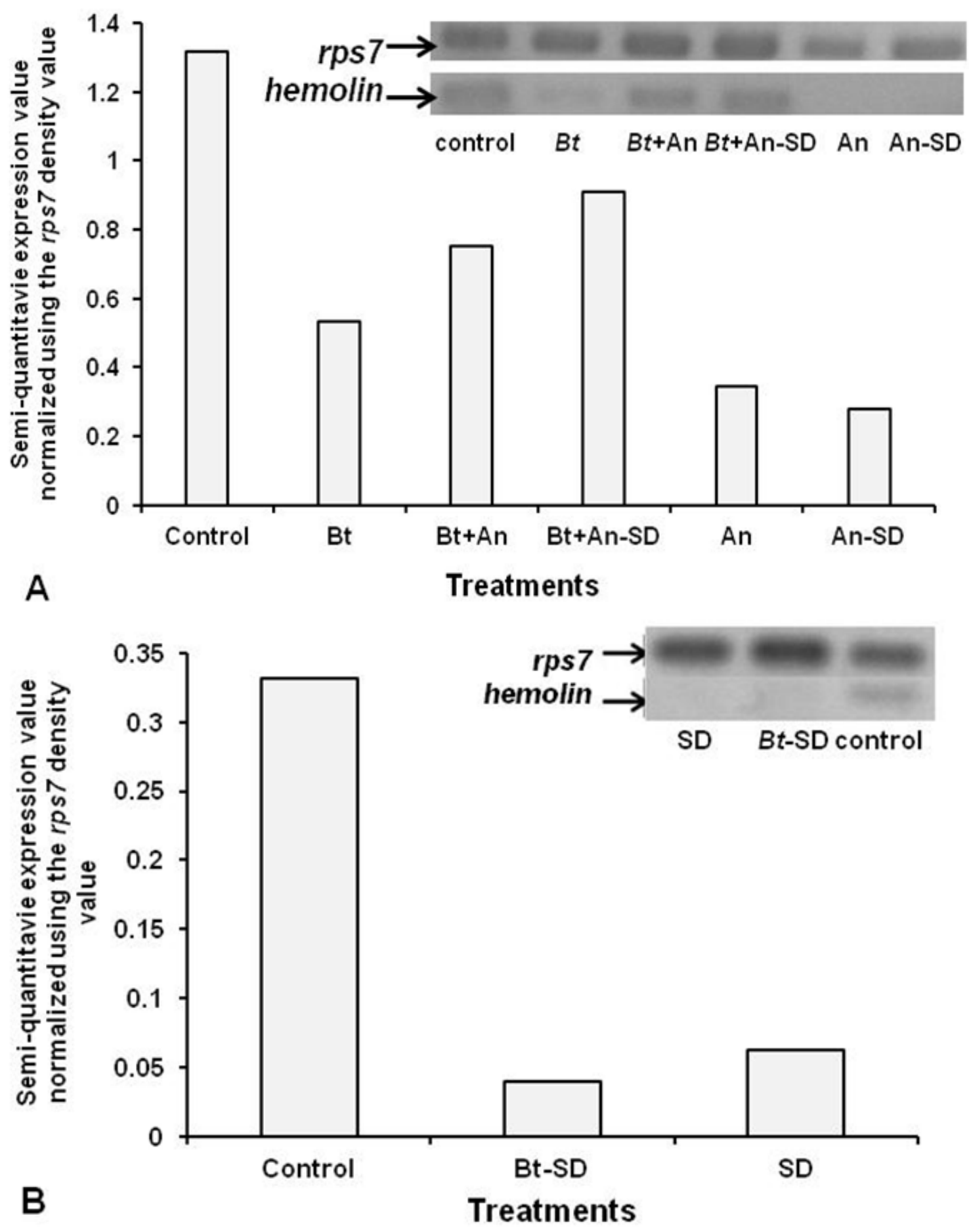